\title{
Non-Isothermal Crystallization Behavior and Thermal Properties of Polyethylene Tuned by Polypropylene and Reinforced with Reduced Graphene Oxide
}

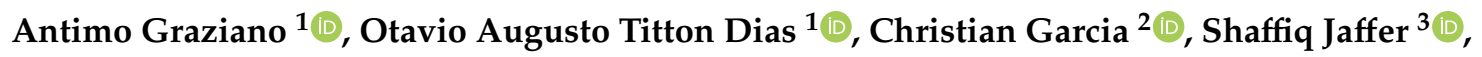 \\ Jimi Tjong ${ }^{1}$ and Mohini Sain ${ }^{1,4, *}$ \\ 1 Centre for Biocomposites and Biomaterials Processing, University of Toronto, 33 Willcocks Street, Toronto, \\ ON M5S 3BS, Canada; antimo.graziano@mail.utoronto.ca (A.G.); otavio.dias@mail.utoronto.ca (O.A.T.D.); \\ jtjong@ford.com (J.T.) \\ 2 Bahen Centre for Information Technology, University of Toronto, 40 St. George Street, Toronto, ON M5S 2E4, \\ Canada; christian.garciasalguero@mail.utoronto.ca \\ 3 TOTAL American Services Inc., 82 South Street, Hopkinton, MA 01748, USA; shaffiq.jaffer@total.ca \\ 4 Department of Mechanical and Industrial Engineering, University of Toronto, 5 King's College Road, \\ Toronto, ON M5S 3G8, Canada \\ * Correspondence: m.sain@utoronto.ca
}

Received: 12 June 2020; Accepted: 19 July 2020; Published: 22 July 2020

\begin{abstract}
This research work is the first to report thermal stability, heat deformation resistance, and crystallization behavior of a Polyethylene (PE)-based biphasic polyolefin system reinforced with Reduced Graphene Oxide (RGO), which was obtained through Graphene Oxide (GO) chemical reduction. Polypropylene (PP) represented the polymeric dispersed phase. A strategic PE/PP/RGO manufacturing procedure was employed to thermodynamically localize RGO at the PE/PP interface, as confirmed by Transmission Electron Microscopy (TEM), bringing a uniform micro phase dispersion into the macro phase. In addition, studies of PE non-isothermal crystallization kinetics indicated that the morphology tunable micro phase and the nanolayered RGO promoted a nucleation-controlled PE crystallization, which was supported by Polarized Light Optical Microscopy (PLOM). This, together with fine morphology, justified the remarkable enhancement registered for the ternary system's thermal stability and heat deformation resistance. Different filler loads were employed, with weight fractions of $2 \%$ and $4 \%$. It was observed that the former, being better exfoliated and more homogeneously distributed at the PE/PP interface than the latter, led to a more improved PE crystallization, alongside a greater ternary system's thermal properties. Moreover, the thermal stability of PE/PP reinforced with $2 \%$ of RGO was even higher than that of virgin PP, while their heat deformation resistance values were found to be similar. Therefore, this unique outcome provides industries, such as the energy and automotive sectors, with the opportunity to substitute PP-rich products with those mostly comprised of a cheaper, more abundant, yet performant PE.
\end{abstract}

Keywords: Reduced Graphene Oxide (RGO); Thermal Gravimetric Analysis (TGA); Heat Deformation Temperature (HDT); Differential Scanning Calorimetry (DSC); non-isothermal crystallization kinetics

\section{Introduction}

Over decades, polymers have been replacing aluminum, metal, and steel in many industrial applications, because they are lightweight, reduce manufacturing expenses, and have improved thermal and mechanical properties [1]. More recently, polymer blending has become a common strategy for producing a novel material that combines the good properties of the two homopolymers, while saving cost, making the unique product suitable for highly demanding applications [2]. Other advantages of 
polymer blending include faster and more flexible manufacturing compared to having to synthesize the final product from scratch, and most importantly, producing sustainable products by recycling plastic waste [3]. The binary system comprised of Polyethylene (PE) and Polypropylene (PP) is gaining a great deal of attention, because both polymers are very abundant and have good processability [4]. Usually, PP has better properties than PE, while the latter is cheaper. Thus, industries are interested in developing a PE/PP binary system, with PE being the major phase. This way, the small amount of PP will not only save cost but will also transfer its good properties to the PE matrix, allowing the manufacturing of a high-performance and cost-effective PE dominant material, which could eventually replace pure PP in many industrial applications. Nevertheless, a positive Gibbs Free Energy for the PE/PP binary system translates into thermodynamic immiscibility between the two polymers. This results in weak interfacial adhesion and hence poor blend properties [5]. A lot of research has been conducted on PE/PP compatibilization by employing a co-polymer as the third component [6], through non-reactive [7] and reactive compatibilization [8]. Nevertheless, targeted fillers, which are solid additives such as fibers, spheres, platelets, etc., have recently been seriously considered as compatibilizers because of their superior properties compared to common copolymers. As a result, this unique co-factor can significantly increase the compatibility between the two polymers and the material's performance [9]. When the employed reinforcing agent is nanosized, its high aspect ratio promotes a very fine dispersion in the binary system, along with a high surface area of interaction with the two polymers. Therefore, nanofillers [10] are replacing conventional fillers [11] in the reinforcement of PE/PP binary systems. However, these novel co-factors are expensive; thus, the mass production of biphasic polyolefin systems reinforced with targeted fillers is very limited [12]. Among all nanofillers, graphene can be synthesized through flexible procedures, such as Graphene Oxide (GO) modification, in a very cheap way [13]. Additionally, graphene has remarkable structural and performance attributes [14]; thus, it can greatly enhance the overall properties of biphasic polyolefin systems, while minimizing cost. One of the most employed GO modification procedures is reduction with hydrazine, leading to Reduced Graphene Oxide (RGO). On the other hand, very few studies have been conducted on the impact of RGO on PE/PP compatibilization and performance enhancement. Tu and coworkers studied how RGO affects PE/PP electrical and mechanical properties, when employing different mixing times and speeds [15], as well as different orders of mixing [16]. However, the literature is lacking reports on PE/PP/RGO thermal stability and heat deformation resistance. In addition, studies of PE crystallization behavior, in the ternary system PE/PP/RGO, are absent. Therefore, the aim of this work is to give a novel and unique contribution to the research by investigating, for the first time, $\mathrm{PE} / \mathrm{PP} / \mathrm{RGO}$ thermal properties such as thermal stability and heat deformation resistance. Estimation of thermal degradation activation energy is also presented, using the Kissinger method [17], for quantifying PE/PP/RGO thermal stability. In addition, this research work reports the first study of PE non-isothermal crystallization kinetics (paired with Polarized Light Optical Microscopy (PLOM) studies), in the ternary system PE/PP/RGO, following the method developed by Liu [18]. Herein, the investigation of isothermal crystallization kinetics is not outlined, since industrial processes are generally conducted under dynamic non-isothermal conditions. Lastly, the thermal stability of the PE-rich material presented here exceeds that of virgin PP, whereas their heat deformation resistance values are similar. Therefore, the key findings of this study open opportunities for industrial sectors, such as energy and automotive, to substitute PP-rich products with those mainly based on a more abundant, cheaper, yet performant PE. This will bring a remarkable progress in the engineering of advanced and lightweight polyolefin-based materials that are suitable for today's high-demanding applications. 


\section{Materials and Methods}

\subsection{Materials}

Isotactic Polypropylene (iPP), with the trade name PPH 3060, was purchased from Total SA, La Porte, TX, USA. The Melt Flow Index (MFI), density, and melting temperature $\left(\mathrm{T}_{\mathrm{m}}\right)$ were $1.8 \mathrm{~g} / 10 \mathrm{~min}$, $0.905 \mathrm{~g} / \mathrm{cm}^{3}$, and $165{ }^{\circ} \mathrm{C}$, respectively. Total SA, La Porte, TX, USA, also supplied High-Density Polyethylene (HDPE), with the trade name BDM2-15/10. Its MFI is $1.2 \mathrm{~g} / 10 \mathrm{~min}$, its density $0.956 \mathrm{~g} / \mathrm{cm}^{3}$, and its $\mathrm{T}_{\mathrm{m}} 134{ }^{\circ} \mathrm{C}$. Sigma-Aldrich, Oakville, ON, Canada, was the supplier of GO, hydrazine monohydrate, and methanol.

\subsection{Preparation of $R G O$}

A fine dispersion of $1.5 \mathrm{~g}$ of as-received $\mathrm{GO}$ in $1.5 \mathrm{~L}$ of deionized water was achieved by sonication, for $2 \mathrm{~h}$. Afterwards, hydrazine monohydrate $(15 \mathrm{~mL})$ was introduced, reacting with GO at $95^{\circ} \mathrm{C}$, for $5 \mathrm{~h}$, under vigorous stirring. Next, washing and filtration were performed with an excess of deionized water, followed by drying at room temperature for $24 \mathrm{~h}$. Lastly, the sample was vacuum dried at $80{ }^{\circ} \mathrm{C}$ for $24 \mathrm{~h}$.

\subsection{Preparation of RGO Filled HDPE/iPP Biphasic Systems}

The synthesis of HDPE/iPP/RGO was performed in two steps. The first one was solution mixing of $0.85 \mathrm{~g}$ of RGO with $4.15 \mathrm{~g}$ of iPP. In detail, the components were added to a flask with $300 \mathrm{~mL}$ of xylenes and mixed for $30 \mathrm{~min}$ at $140{ }^{\circ} \mathrm{C}$, under stirring and nitrogen atmosphere. Then, precipitation of the hot content of the flask was performed in $300 \mathrm{~mL}$ of methanol, followed by filtration. Afterwards, washing with plenty of deionized water was performed to remove most of the xylenes/methanol solution. Following this, the sample was first dried at room temperature for $24 \mathrm{~h}$ and then vacuum dried at $80^{\circ} \mathrm{C}$ for $24 \mathrm{~h}$ to completely remove any remaining trace of solvent. The second step was melt mixing, in a Brabender batch mixer, $7 \mathrm{~g}$ of the masterbatch iPP/RGO with $53 \mathrm{~g}$ of HDPE. However, in order to achieve a better dispersion of $\mathrm{iPP} / \mathrm{RGO}$ into $\mathrm{HDPE}$, the latter was first fully melted at $180{ }^{\circ} \mathrm{C}$ for $3 \mathrm{~min}$ at a rotor speed of $80 \mathrm{rpm}$, and only afterwards, iPP/RGO was introduced. At this point, the speed was increased to $120 \mathrm{rpm}$, and the mixing was performed for $2 \mathrm{~min}$ at $180{ }^{\circ} \mathrm{C}$. During this two-step manufacturing procedure, the co-factor was thermodynamically driven to self-localize at the biphasic polyolefin system interface, as explained in detail in Section 3.1. A 90/10 weight ratio was chosen for HDPE/iPP, and the weight fraction of RGO was $2 \%$. One of the objectives of this research work was to investigate the impact of filler amount on the material's properties. Thus, biphasic polyolefin systems with $4 \mathrm{wt} \%$ of RGO were also produced. In addition, for comparison purposes, unfilled binary systems, as well as those filled with GO, were synthesized as well. Lastly, for simplicity, sample denotations were generated (Table 1).

Table 1. Sample denotations and weight fractions. GO: Graphene Oxide, HDPE: High-Density Polyethylene, iPP: Isotactic Polypropylene, PE: Polyethylene, RGO: Reduced Graphene Oxide.

\begin{tabular}{ccccc}
\hline Denotations & HDPE (wt \%) & iPP (wt \%) & GO (wt \%) & RGO (wt \%) \\
\hline PE90 & 90 & 10 & 0 & 0 \\
PE90GO2 & 88.2 & 9.8 & 2 & 0 \\
PE90RGO2 & 88.2 & 9.8 & 0 & 2 \\
PE90GO4 & 86.4 & 9.6 & 4 & 0 \\
PE90RGO4 & 86.4 & 9.6 & 0 & 4 \\
\hline
\end{tabular}

\subsection{Thermal Gravimetric Analysis (TGA)}

TGA was carried out with a Thermal Gravimetric Analyzer, TA instruments TGA Q500, Pittsburgh, PA, USA. Each sample underwent degradation from room temperature to $600^{\circ} \mathrm{C}$, in nitrogen atmosphere, 
at four different heating rates $\left(10,20,30\right.$, and $\left.40^{\circ} \mathrm{C} / \mathrm{min}\right)$. The material's thermal stability was quantified by estimating the activation energy of thermal degradation $\left(E_{T}\right)$, following the Kissinger method: [19].

$$
\ln \left(\frac{\beta_{0}}{T_{\max }^{2}}\right)=\ln \left(\frac{A \times R}{E_{T}}\right)-\frac{E_{T}}{R \times T_{\max }} .
$$

$R$ is the gas constant, $T_{\max }$ is the temperature of maximum degradation, $\beta_{0}$ is the cooling rate, and $\mathrm{A}$ is the pre-exponential factor. $E_{T}$ could be calculated from the slope of the plot " $\ln \left(\beta_{0} / T_{\max }{ }^{2}\right)$ " versus " $1 / T_{\max }$ ". Tests were redone two more times to incorporate the standard deviation values.

\subsection{Heat Deformation Temperature (HDT) Characterization}

HDT was measured employing a Q800 DMA analyzer (TA Instruments, Pittsburgh, PA, USA). The testing method was three-point bending, and the heating rate was $2{ }^{\circ} \mathrm{C} / \mathrm{min}$, from room temperature to $70^{\circ} \mathrm{C}$. Each sample had a length of $50 \mathrm{~mm}\left(L_{D M A}\right)$, a width of $5.5 \mathrm{~mm}\left(W_{D M A}\right)$, and a thickness of $0.45 \mathrm{~mm}\left(T_{D M A}\right)$. By following ASTM D648, a 0.455 MPa stress $(\sigma)$ was applied, and the Dynamic Mechanical Analysis (DMA) analyzer was set to show the plot "sample strain" (or sample deflection) versus "temperature". The strain (or deflection) at which the deflection temperature was taken could be calculated through the following procedure. Given the applied stress $(0.455 \mathrm{MPa})$ and the sample dimensions, Equation (2) allowed the calculation of the applied force $(F)$ :

$$
F=\frac{2}{3}\left[\sigma\left(\frac{T_{D M A}^{2} \times W_{D M A}}{L_{D M A}}\right)\right] .
$$

In our case, $F=6.8 \mathrm{kN}$. Next, the strain $(\varepsilon)$ in the American Society for Testing and Materials (ASTM) sample, at a deflection $\left(d_{A S T M}\right)$ of $0.25 \mathrm{~mm}$, could be calculated:

$$
\varepsilon=6\left(\frac{d_{A S T M} \times T_{A S T M}}{L_{\text {ASTM }}^{2}}\right)=0.00121=0.121 \% .
$$

$T_{A S T M}=13 \mathrm{~mm}$ and $L_{A S T M}=127 \mathrm{~mm}$ are the sample thickness and length, respectively, according to ASTM D648. Lastly, the sample deflection $\left(d_{D M A}\right)$ at which the deflection temperature was taken could be calculated:

$$
d_{D M A}=\varepsilon\left[\frac{L_{D M A}^{2}}{\left(6 \times T_{D M A}\right)}\right] .
$$

In our case, $d_{D M A}=1.8 \mathrm{~mm}$. Four specimens were considered for each test.

\subsection{Differential Scanning Calorimetry (DSC)}

DSC tests were performed using a Q1000 Differential Scanning Calorimeter, from TA Instruments, Pittsburgh, PA, USA. In nitrogen atmosphere, each sample was first heated from room temperature to $180^{\circ} \mathrm{C}$ to erase thermal history and then cooled down to room temperature, which was followed by reheating up to $180^{\circ} \mathrm{C}$. The heating and cooling cycles were performed at a rate of $10^{\circ} \mathrm{C} / \mathrm{min}$. Tests were redone two more times to incorporate the standard deviation values. Crystallization temperature $\left(T_{c}\right)$, melting point $\left(T_{m}\right)$, and percentage crystallinity $\left(X_{c}\right)$ of PE in the samples PE90, PE90GO2, PE90RGO2, PE90GO4, and PE90RGO4 were obtained from cooling thermogram, heating thermogram, and Equation (5), respectively:

$$
X_{c}=\frac{\Delta H}{w_{P E} \times \Delta H_{0}} \times 100 .
$$

$\Delta H_{0}$ indicates the melting enthalpy of PE for $100 \%$ crystallinity, and its value is $293 \mathrm{~J} / \mathrm{g}$ [20]. Conversely, the melting enthalpy of $\mathrm{PE}$ is represented by $\Delta \mathrm{H}$. Moreover, the data were normalized 
to account for the content of micro phase (PP) and filler (GO or RGO). Indeed, $w_{P E}$ is the PE weight fraction in each sample. Studies of PE non-isothermal crystallization kinetics in unfilled and filled binary systems were performed by running DSC tests at cooling rates of $10,15,20$, and $25^{\circ} \mathrm{C} / \mathrm{min}$. The Kissinger method [21] allowed the calculation of the activation energy of crystallization $\left(E_{c}\right)$ of $\mathrm{PE}$, in the different samples investigated, by considering the variation of crystallization temperature as a function of the cooling rate:

$$
\frac{\left[\ln \left(\frac{\beta_{0}}{T_{c}^{2}}\right)\right]}{\frac{1}{T_{c}}}=\frac{-E_{c}}{R} .
$$

The crystallization temperature of PE is represented by $T_{c}$. $R$ indicates the gas constant, while $\beta_{0}$ represents the cooling rate. The slope of the plot " $\ln \left(\beta_{0} / T_{c}^{2}\right)$ " versus " $1 / T_{c}$ " gave the value of $E_{c}$. Tests were redone two more times to incorporate the standard deviation values.

The Liu method [18] was employed to obtain another PE crystallization parameter, $F(T)$, which is related to the cooling rate needed to obtain a certain crystallinity degree, at unit crystallization time:

$$
\log \beta_{0}=\log F(T)-b \log t_{c} .
$$

The Avrami/Ozawa exponents ratio is indicated by $b=n / m$, while $\beta_{0}$ represents the cooling rate, and $t_{c}$ represents the crystallization time. Equation (8) allowed the calculation of the crystallization time:

$$
t_{c}=\frac{T_{0}-T_{c}}{\beta_{0}}
$$

The temperature at which crystallization starts is indicated by $T_{0}$. The intercept with the $\mathrm{x}$ axes of the " $\ln \left(\beta_{0}\right)$ " versus " $\ln \left(t_{c}\right)$ " plot generated the value of $F(T)$. Tests were redone two more times to incorporate the standard deviation values. The Khanna method [22] was employed to estimate the PE "crystallization rate coefficient" (CRC), which is indicative of the rate of the non-isothermal crystallization:

$$
C R C=\frac{\Delta \beta_{0}}{\Delta T_{C}} .
$$

The $C R C$ value was obtained from the slope of the " $\beta_{0}$ " versus " $T_{\mathcal{c}}$ " plot. Tests were redone two more times to incorporate the standard deviation values.

\subsection{TEM}

The exfoliation state of GO and RGO, as well as its localization (inside the PE phase, inside the PP phase, or at the PE/PP interface) were investigated with a Transmission Electron Microscope, FEI Tecnai 20, Wilmington, NC, USA. A diamond knife was used to cryogenically cut each sample at $-140^{\circ} \mathrm{C}$, obtaining ultrathin films. Then, these were placed onto carbon-coated $\mathrm{Cu}$ grids, with standard 400 mesh. TEM images were taken at an accelerating voltage of $200 \mathrm{kV}$.

\subsection{PLOM}

A Polarized Light Microscope, Olympus BX50 (Spectra Services, Ontario, NY, USA), was employed to observe the PE crystal growth and size distribution. Each specimen ( $50 \mu \mathrm{m}$ thick) was embedded between two glass cover slips and then heated up to $180{ }^{\circ} \mathrm{C}$ by using a hot stage, Linkam TMS 94 (Linkam Scientific Instruments, Tadworth, UK). This temperature was held for $3 \mathrm{~min}$, ensuring the complete melting of the sample, hence the removal of thermal history. Afterwards, a quick cooling to $115^{\circ} \mathrm{C}$ was performed, and this temperature was held to observe isothermal crystal growth. Images were taken after 5 min by using a Charged Coupled Device (CCD) camera, Donpisha XC-003 (Spectra Services, Ontario, NY, USA). The spherulite average diameter $\left(d_{\text {avg }}\right)$ was measured with the software 
ImageJ through the following procedure: the cross-sectional area of each sphere $\left(A_{i}\right)$ was first measured, and then the equivalent diameter $\left(d_{i}\right)$ was calculated:

$$
d_{i}=2 \sqrt{A_{i} / \pi}
$$

$A_{i}$ and $d_{i}$ were then used to calculate $d_{a v g}$. For this purpose, roughly 100 spherulites were considered per each sample.

\section{Results and Discussion}

\subsection{Schematic of RGO Synthesis and Morphological Configuration of Unfilled and Filled Binary Systems}

Figure 1 shows a schematic of RGO synthesis via GO reduction (explained step by step in Section 2.2).

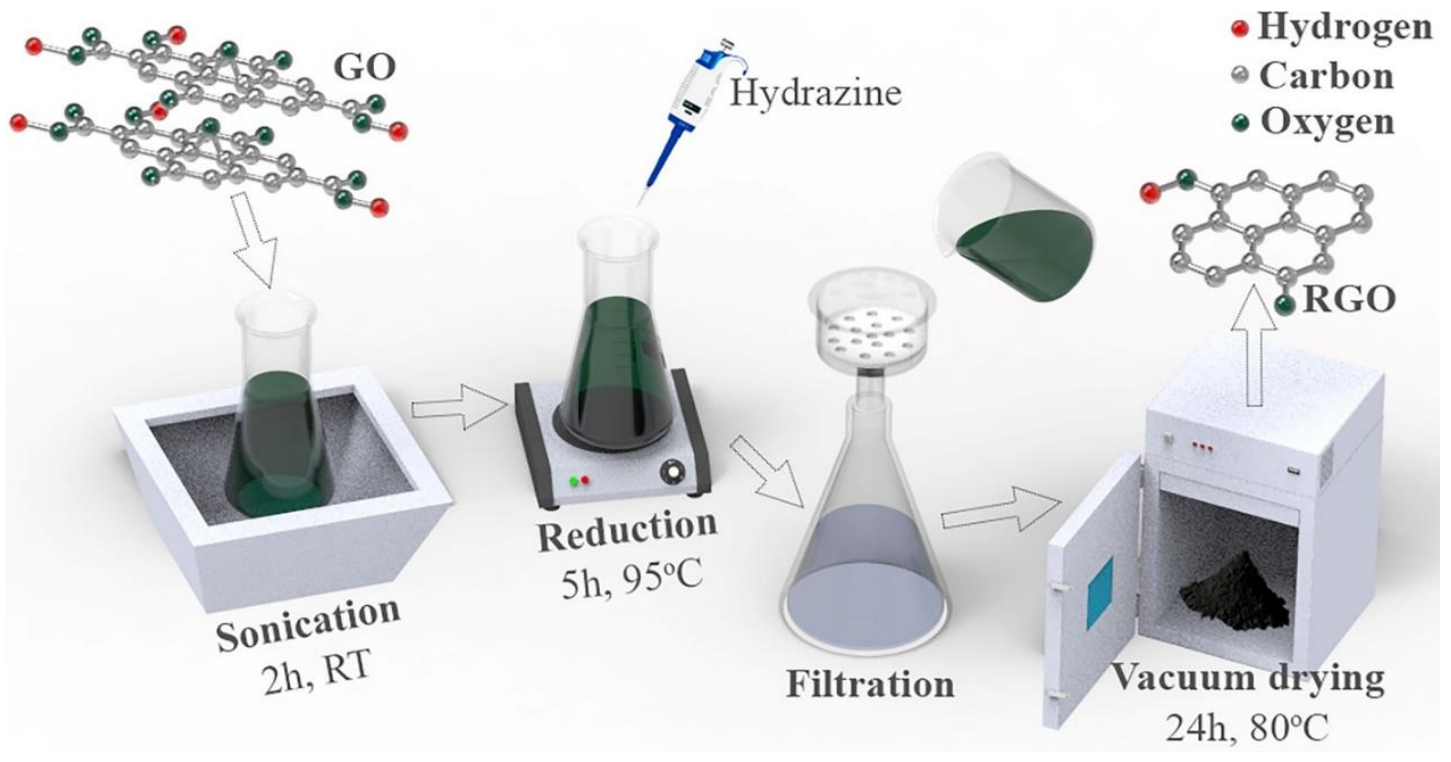

Figure 1. Schematic of RGO synthesis.

GO has several oxygen-related functionalities, being hydroxyl, carboxyl, epoxy, and carbonyl moieties [23]. Upon reduction with hydrazine, most of these functional groups were removed from the main lattice, almost fully recovering the pure graphene structure. Indeed, as can be seen from Figure 1, RGO had very few oxygen-containing moieties, compared to GO, with the $\mathrm{sp}^{2}$ graphitic structure being mostly restored. This is supported by the experimental findings reported in the Supplementary Materials of our recent study [24]. In addition, GO reduction led to a co-factor (RGO) that had an improved exfoliation degree (fewer stacked layers), reduced interlayer distance, and increased aspect ratio and surface area, as shown in other research studies [25].

TEM micrographs of PE90, PE90GO2, PE90RGO2, PE90GO4, and PE90RGO4 are illustrated in Figure 2, with the intent of investigating GO and RGO exfoliation degree and dispersion state (PE phase, PP phase, or PE/PP interface).

In all the images, a PP droplet can be seen roughly in the center (smooth area), whereas the major phase (PE) is the rough area around. For filled binary systems, the co-factor was always localized at the PE/PP interface. This was the expected outcome of our strategic mixing of the three components. Nevertheless, RGO had a greater exfoliation degree and was better distributed at the blend interface (Figure 2C,E) compared to GO (Figure 2B,D), because the co-factor obtained upon chemical reduction (RGO) was better exfoliated and had less stacked layers than GO. When comparing RGO2 with RGO4, the latter had an agglomerated structure (Figure 2E) compared to the former (Figure 2C), since there was a restacking of graphitic platelets upon increasing the filler amount, due to Van der Waals attractions between the layers [26]. Consequently, compared to PE90RGO4 (Figure 2E), the most homogeneous 
distribution of the co-factor at the PE/PP interface was observed in the case of PE90RGO2 (Figure 2C). This also led to the most uniform minor phase dispersion into the major phase, with the PP size being the smallest, as indicated by Scanning Electron Microscopy (SEM) studies in our previous work [24]. Therefore, since morphology is usually correlated with properties, PE90RGO2 should have the greatest performance. Thermal properties characterization (Section 3.2) validated this hypothesis.

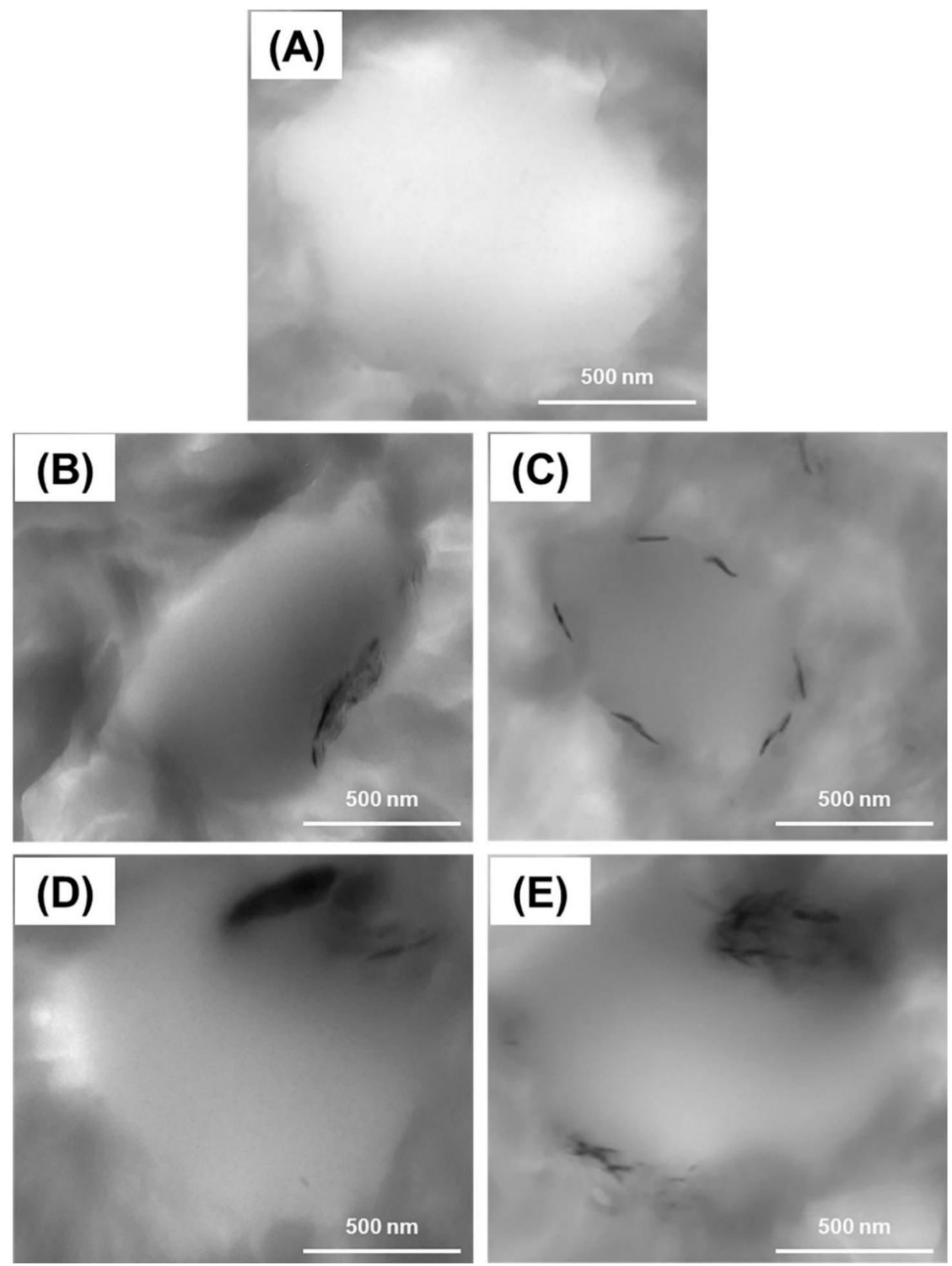

Figure 2. TEM images of PE90 (A), PE90GO2 (B), PE90RGO2 (C), PE90GO4 (D), and PE90RGO4 (E). 
Figure 3 graphically explains step two of the manufacturing process of PE/PP/GO (Figure 3A,B) and PE/PP/RGO (Figure 3C,D). The denotations $t=0$ and $t=2 \mathrm{~min}$ represent the beginning and end of the mixing between the $\mathrm{PP} /$ Filler and $\mathrm{PE}$, respectively.

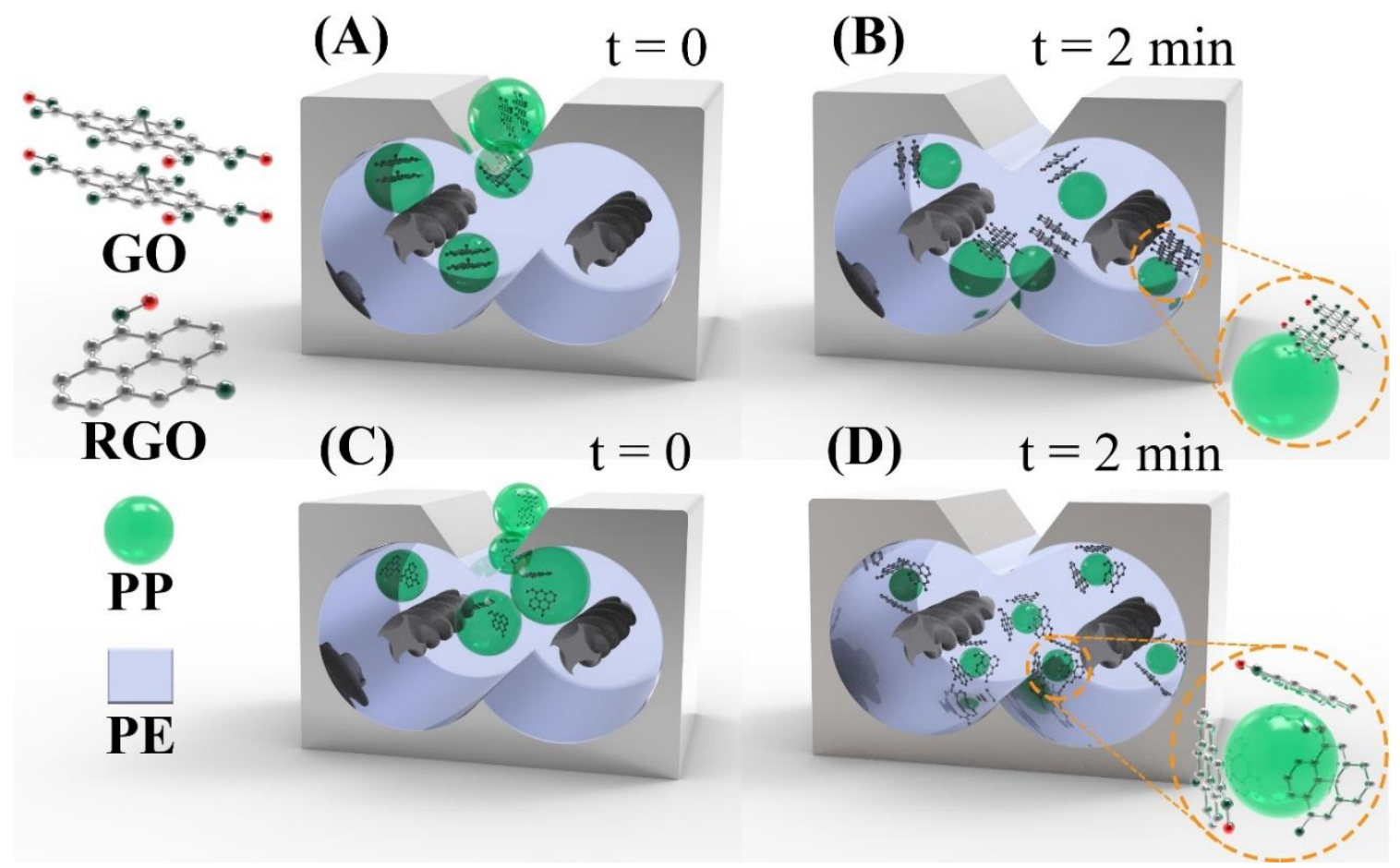

Figure 3. Mechanistic representation of morphological configuration of PE/PP/GO (A and B) and $\mathrm{PE} / \mathrm{PP} / \mathrm{RGO}$ (C and $\mathbf{D}$ ) during step two of the ternary system synthesis.

As can be seen from Figure 3B,D, the sequential mixing procedure induced GO and RGO to be selectively localized at the biphasic system interface. This was thermodynamically explained in our previous research work [24], and a brief description is given as follows. The surface energy (SE) values of PE, PP, GO, and RGO were 38.4, 34.2, 132.3, and $115.3 \mathrm{~mJ} / \mathrm{m}^{2}$, respectively. Since GO and RGO had SE values closer to that of PE than that of PP, the co-factor preferred to be dispersed into the major phase. Thus, when employing step two of the ternary system manufacturing procedure (PP/Filler mixed with $\mathrm{PE}$ ), the co-factor migrated from the micro phase to the macro phase. At the same time, the mixing speed and time were controlled appropriately to induce the filler to stop its migration in time to localize itself at the PE/PP interface. Nevertheless, because of the presence of many oxygen-related functionalities on its structure, GO has a multilayered and agglomerated configuration [27]. Consequently, it was not homogeneously distributed at the PE/PP interface (Figure 3B, as well as Figure 2B,D), and PP was not uniformly dispersed in PE, as confirmed by SEM analysis in our recent work [24]. Therefore, the PE/PP/GO properties were barely enhanced. On the other hand, RGO was better exfoliated, with a higher aspect ratio, thus being more homogeneously distributed at the PE/PP interface (Figure 3D, as well as Figure 2C,E) with respect to GO. This led to a much finer PE/PP/RGO morphology, with PP being smaller in size and having a more uniform droplet diameter distribution, compared to what was seen for PE/PP/GO [24]. Consequently, a significant increase in $\mathrm{PE} / \mathrm{PP} / \mathrm{RGO}$ performance was registered (specifically thermal properties), as shown in Section 3.2.

\subsection{Thermal Properties of Unfilled and Filled Binary Systems}

Figure $4 \mathrm{~A}$ illustrates the TGA curves (at a rate of $10^{\circ} \mathrm{C} / \mathrm{min}$ ) of unfilled and filled binary systems, whereas the insert graph represents the TGA curves of pure GO and RGO. Figure 4B depicts the 
weight derivative over temperature for unfilled and filled binary systems. Table 2 indicates $\mathrm{Td}_{99}$, the temperature at which thermal degradation begins, $\mathrm{Td}_{50}$, the temperature referring to $50 \%$ weight loss, and $\operatorname{Td}_{10}$, the temperature indicating $90 \%$ weight loss. These temperatures could be obtained from the main TGA graph. Table 2 also shows $\mathrm{Td}_{\max }$ (temperature of maximum degradation), which could be measured from the insert TGA graph.
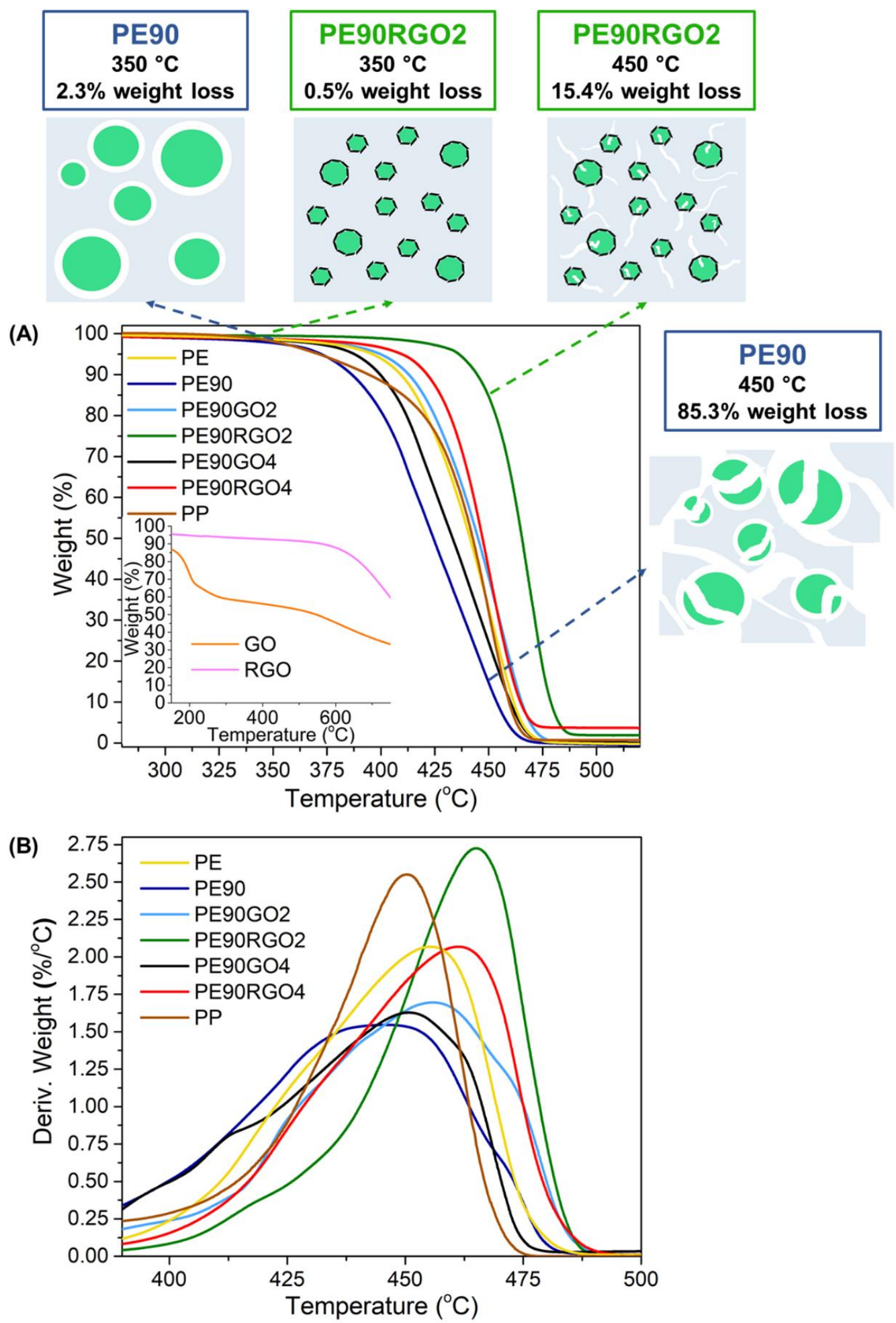

Figure 4. Weight over temperature (A) and derivative of weight over temperature (B) for unfilled and filled binary systems. (The insert graph of Figure $4 \mathrm{~A}$ depicts weight over temperature for pure GO and RGO). 
Table 2 also depicts the HDT values for unfilled and filled blends.

Table 2. Thermal properties of unfilled and filled binary systems. HDT: Heat Deformation Temperature.

\begin{tabular}{ccccccc}
\hline & $\mathbf{T d}_{\mathbf{9 9}}\left({ }^{\circ} \mathbf{C}\right)$ & $\mathbf{T d}_{\mathbf{5 0}}\left({ }^{\circ} \mathbf{C}\right)$ & $\operatorname{Td}_{\mathbf{1 0}}\left({ }^{\circ} \mathbf{C}\right)$ & $\mathbf{T d}_{\max }\left({ }^{\circ} \mathbf{C}\right)$ & $\mathbf{E}_{\mathbf{T}}(\mathbf{K J} / \mathbf{m o l})$ & HDT $\left({ }^{\circ} \mathbf{C}\right)$ \\
\hline PE & $340( \pm 1.6)$ & $442( \pm 1.4)$ & $463( \pm 1.4)$ & $455( \pm 1.5)$ & $159.4( \pm 0.6)$ & $48.6( \pm 0.5)$ \\
PE90 & $301( \pm 1.4)$ & $422( \pm 1.7)$ & $456( \pm 1.1)$ & $443( \pm 1.2)$ & $124.2( \pm 0.9)$ & $47.2( \pm 0.4)$ \\
PE90GO2 & $334( \pm 1.1)$ & $451( \pm 1.3)$ & $465( \pm 1.2)$ & $457( \pm 1.4)$ & $162.1( \pm 1.1)$ & $57.3( \pm 0.5)$ \\
PE90RGO2 & $359( \pm 1.2)$ & $462( \pm 1.2)$ & $487( \pm 1.3)$ & $467( \pm 1.1)$ & $238.7( \pm 0.7)$ & $66.7( \pm 0.3)$ \\
PE90GO4 & $326( \pm 1.2)$ & $435( \pm 1.1)$ & $456( \pm 1.2)$ & $451( \pm 1.4)$ & $153.6( \pm 0.8)$ & $52.4( \pm 0.4)$ \\
PE90RGO4 & $335( \pm 1.4)$ & $456( \pm 1.1)$ & $466( \pm 1.1)$ & $462( \pm 1.3)$ & $196.8( \pm 0.6)$ & $59.9( \pm 0.4)$ \\
PP & $339( \pm 1.3)$ & $441( \pm 1.2)$ & $457( \pm 1.4)$ & $450( \pm 1.3)$ & $157.1( \pm 0.8)$ & $70.8( \pm 0.3)$ \\
\hline
\end{tabular}

Furthermore, the quantification of the material's thermal stability was performed by calculating $\mathrm{E}_{\mathrm{T}}$ (Table 2). For this purpose, four different heating rates were employed, as explained in Section 2.4. Figure 5 shows the plots of " $\ln \left(\beta_{0} / T_{\max }{ }^{2}\right)$ " versus " $1 / T_{\max }$ ", and the activation energy value was taken from the slope.

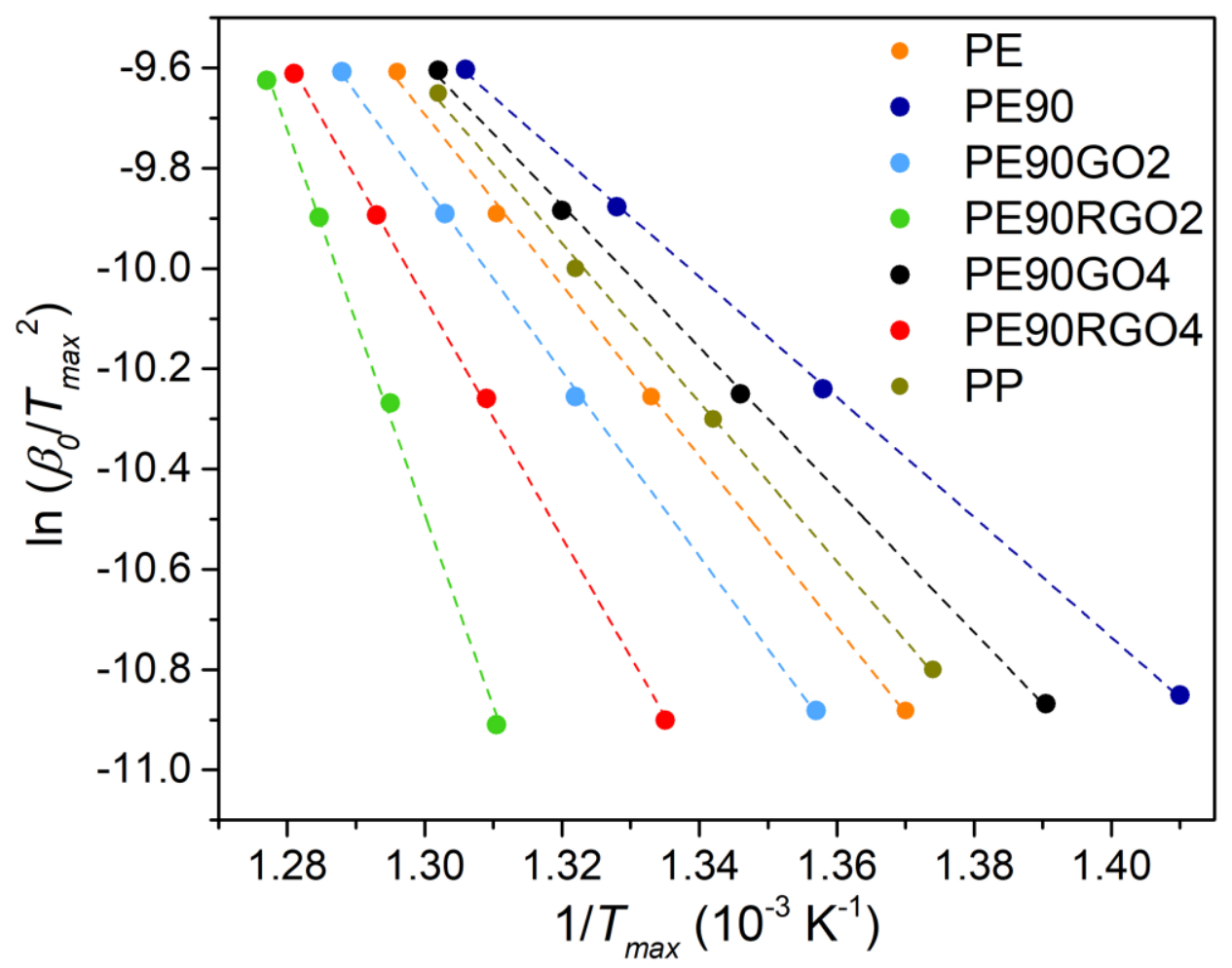

Figure 5. Kissinger plots for activation energy of thermal degradation of unfilled and filled binary systems.

Compared to the neat binary system (PE90), $\mathrm{Td}_{99}, \mathrm{Td}_{50}, \mathrm{Td}_{10}, \mathrm{Td}_{\max }, \mathrm{E}_{\mathrm{T}}$, and HDT were higher for filled biphasic systems because of the co-factor gas barrier activity, which hindered the gaseous molecules' diffusion coming from the two polymers [28]. Consequently, the thermal decomposition was delayed, and the thermal stability was increased. The co-factor, placed at the blend interface, also improved the PE/PP interfacial adhesion, thus enhancing the material's heat deformation resistance [29]. A higher boost in thermal properties was registered when introducing RGO as a filler, instead of $\mathrm{GO}$, as the more uniformly distributed co-factor not only led to stronger interactions between the two polymeric phases but also formed stronger charred layers on the polymers' surfaces, thus more efficiently disrupting the volatile degraded matter [30]. Moreover, RGO4 had a lower impact on the material's thermal performance compared to RGO2, because the former was more agglomerated (Figure 2E) than the latter (Figure 2C), hence not bringing high PE/PP interfacial adhesion and not 
preventing the emission of gaseous molecules during the decomposition of the two polymers as effectively as RGO2. Another outcome of the performed TGA study was that above $500^{\circ} \mathrm{C}$, the residual (non-degraded) PE90RGO2 sample was $2 \mathrm{wt} \%$, while the non-degraded PE90RGO4 was about $4 \mathrm{wt} \%$. These quantities represented the co-factor weight content in the two ternary systems. This is demonstrated by the insert graph in Figure 3A. Since RGO begins to degrade only after $600{ }^{\circ} \mathrm{C}$, the samples PE90RGO2 and PE90RGO4 still contain the full amount of RGO in them at a temperature of about $500{ }^{\circ} \mathrm{C}$. The insert graph in Figure $3 \mathrm{~A}$ also demonstrates that the thermal stability of pure GO and RGO is higher than that of the polymeric ternary systems, especially at high temperatures. Moreover, Figure 4 A shows that PE90 lost $2.3 \%$ of its total weight at $350{ }^{\circ} \mathrm{C}$, while $85.3 \%$ was lost at $450{ }^{\circ} \mathrm{C}$. On the other hand, the PE90RGO2 weight loss was $0.5 \%$ at $350{ }^{\circ} \mathrm{C}$ and $15.4 \%$ at $450{ }^{\circ} \mathrm{C}$. Therefore, in the temperature range of $100^{\circ} \mathrm{C}$, a huge difference in weight loss was observed for PE90, whereas a less significant weight loss occurred for PE90RGO2. The reason why this happened is graphically explained by the 2D drawings in Figure 4. PE90 is comprised of two immiscible polymers (PE and PP); thus, its weakest point is the PE/PP interface. This means that at high temperatures (for example $450{ }^{\circ} \mathrm{C}$ ), a high degree of material degradation is expected to take place at the blend interface, followed by the propagation of the cracks through the macro phase (PE) and the micro phase (PP), causing larger cracks. Conversely, in the PE90RGO2 system, RGO was almost homogeneously distributed at the blend interface. This increased the interfacial adhesion between the two polymer phases, thus making the PE/PP interface stable. As a result, a less severe thermal degradation should be observed, with much smaller fractures occurring in the PE and PP phases, even at high temperatures, e.g., $450^{\circ} \mathrm{C}$, therefore leading to a more thermally stable material. Lastly, Figures 4 and 5, as well as Table 2, indicate that the TGA temperatures and $\mathrm{E}_{\mathrm{T}}$ of PE90RGO2 were higher than those of virgin PP, while the HDT value of PP was not too far from that of PE90RGO2. Our previous work showed that PE90RGO2 was better performant than neat PP in the case of mechanical properties, too (strength, stiffness, and toughness) [24]. This proved that the proposed GO chemical reduction and sequential mixing of the three components yielded a highly performant PE-rich product that has the potential to replace more expensive PP-based ones in energy and automotive industries for today's highly demanding applications.

\subsection{PE Spherulitic Morphology}

Figure 6 represents PLOM images of PE crystal growth in the different systems considered. In the case of a neat binary system (Figure 6A), only few big PE crystals are seen. Since the two polymers are immiscible, PP has no ability to influence PE spherulite growth. Conversely, once the co-factor was added (Figure 6B-E) and localized at the binary system interface (Figure 2B-E), thanks to the employed strategic mixing of the three components, droplet coalescence was hindered, and a finer dispersion of the minor phase into the major phase was registered, as confirmed by the SEM analysis outlined in our previous work [24]. Consequently, PP provided more nucleating sites for PE crystallization, increasing the spherulitic nucleation density [31].

As can been seen from Figure 6C, the best nucleating process for PE crystallization is constituted by the synergistic addition of PP and RGO2. Indeed, among all the systems under investigation, PE90RGO2 was the one in which the highest nucleation density of PE was observed, with its spherulites being the smallest, as well as the most uniform in size. In addition, the calculated average diameter of PE crystals in the PE90RGO2 system was $2.2( \pm 0.1) \mu \mathrm{m}$, while it was $28.8( \pm 0.3), 13.6( \pm 0.2), 18.9( \pm 0.3)$, and $6.7( \pm 0.2) \mu \mathrm{m}$ in the configurations PE90, PE90GO2, PE90GO4, and PE90RGO4, respectively. The values in parentheses represent the standard deviation. Furthermore, PE had the fastest and easiest crystallization in the PE90RGO2 system, because RGO2 was highly exfoliated and homogeneously distributed at the PE/PP interfacial area (Figure 2E). This promoted a much more uniform minor phase dispersion into the major phase compared to the other ternary systems investigated (proven, in our previous work [24], by SEM studies), hence increasing the number of heterogeneous sites for PE 
crystals to grow. It is also possible that the RGO2-saturated interfacial area between the two polymeric phases served as an extra heterogeneity for the nucleation of PE [32].
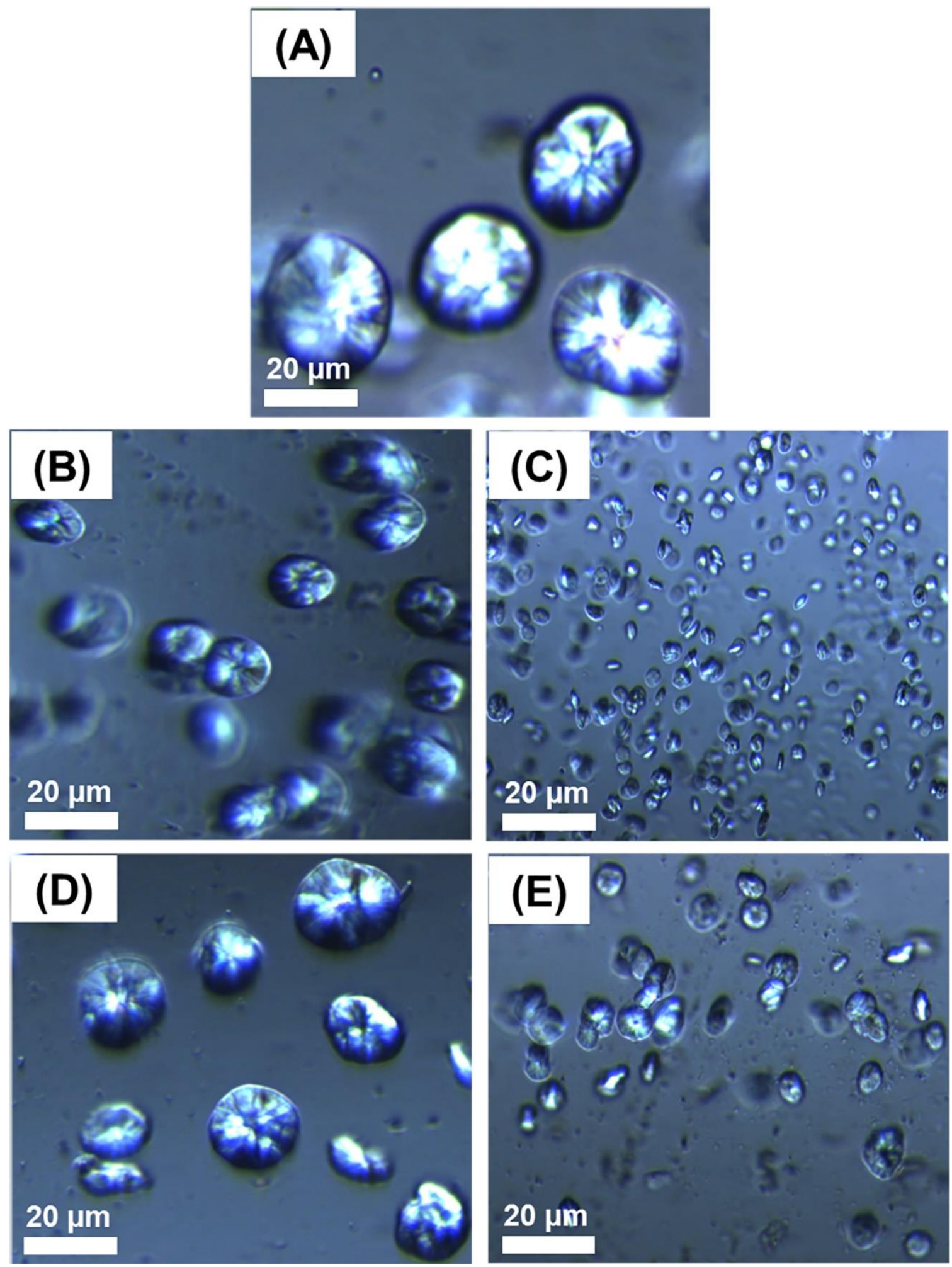

Figure 6. Polarized Light Optical Microscopy (PLOM) micrographs of PE crystal growth in PE90 (A), PE90GO2 (B), PE90RGO2 (C), PE90GO4 (D), and PE90RGO4 (E). 


\subsection{PE Thermal and Crystallization Behavior in Unfilled and Filled Binary Systems}

Figure 7 depicts cooling and heating thermograms of PE in unfilled and filled biphasic systems at cooling and heating rates of $10{ }^{\circ} \mathrm{C} / \mathrm{min}$.

(A)

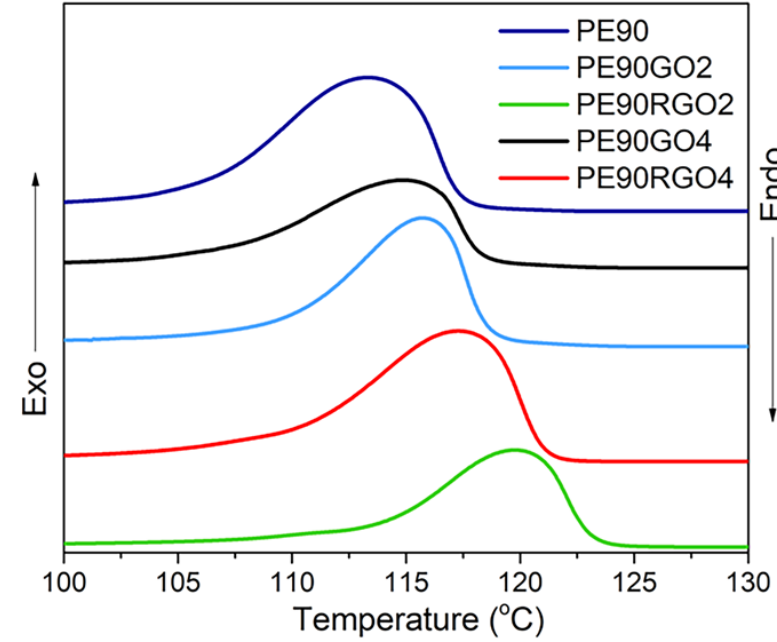

(B)

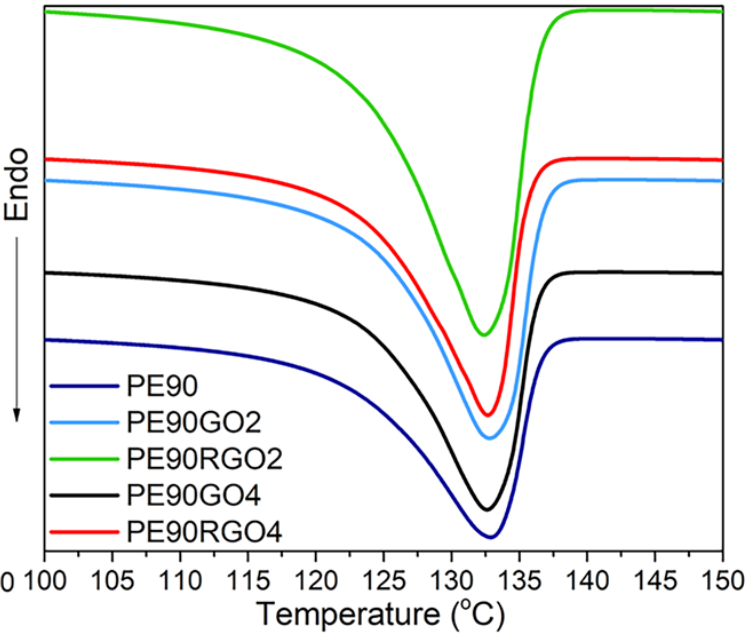

Figure 7. Cooling (A) and heating (B) thermograms of PE in unfilled and filled binary systems.

$\mathrm{T}_{\mathrm{c}}, \mathrm{T}_{\mathrm{m}}, \mathrm{X}_{\mathrm{c}}, \mathrm{t}_{\mathrm{c}}$, and supercooling $\left(\Delta \mathrm{T}=\mathrm{T}_{\mathrm{m}}-\mathrm{T}_{\mathrm{c}}\right)$ could be determined from the cooling thermogram (Figure 7A), and they are represented in Table 3.

Table 3. Crystallization and thermal parameters of PE in unfilled and filled binary systems.

\begin{tabular}{cccccc}
\hline & $\mathbf{T}_{\mathbf{c}}\left({ }^{\circ} \mathbf{C}\right)$ & $\mathbf{T}_{\mathbf{m}}\left({ }^{\circ} \mathbf{C}\right)$ & $\Delta \mathbf{T}\left({ }^{\circ} \mathbf{C}\right)$ & $\mathbf{t}_{\mathbf{c}}(\mathbf{m i n})$ & $\mathbf{X}_{\mathbf{c}}(\mathbf{\%})$ \\
\hline PE90 & $113.4( \pm 1.4)$ & $132.6( \pm 0.6)$ & $19.2( \pm 0.6)$ & $0.53( \pm 0.04)$ & $62.1( \pm 0.8)$ \\
PE90GO2 & $116.3( \pm 1.1)$ & $132.4( \pm 0.6)$ & $16.1( \pm 0.4)$ & $0.40( \pm 0.01)$ & $64.8( \pm 0.9)$ \\
PE90RGO2 & $120.6( \pm 2.6)$ & $132.2( \pm 0.8)$ & $11.6( \pm 0.4)$ & $0.29( \pm 0.06)$ & $74.3( \pm 1.1)$ \\
PE90GO4 & $114.9( \pm 1.1)$ & $132.5( \pm 0.5)$ & $17.6( \pm 0.5)$ & $0.45( \pm 0.02)$ & $62.9( \pm 0.9)$ \\
PE90RGO4 & $117.8( \pm 1.2)$ & $132.3( \pm 0.7)$ & $14.5( \pm 0.5)$ & $0.38( \pm 0.02)$ & $66.3( \pm 0.7)$ \\
\hline
\end{tabular}

According to the literature, an increase in $\mathrm{T}_{\mathrm{c}}$ and a decrease in $\mathrm{t}_{\mathrm{c}}$ indicate nucleation-controlled polymer crystallization [33]. Furthermore, when a polymer crystallizes with less supercooling, it crystallizes more perfectly [34]. Table 3 shows that PE90RGO2 was characterized by the highest $\mathrm{T}_{\mathrm{C}}$ and $X_{c}$, as well as the lowest $t_{c}$. Moreover, even though $T_{m}$ hardly changed for all the samples under consideration, the minimum value of $\triangle \mathrm{T}$ was reached in the case of PE90RGO2. Therefore, the best nucleating effect on PE crystallization was achieved when the micro phase PP was paired with the co-factor RGO2, since the latter was highly exfoliated and selectively localized at the binary system interface, bringing a high surface area of interaction with the two polymers, hence increasing their synergy. This is also validated by other works [35,36] available in the literature, which study the crystallization of PE in nanocomposites by means of Small Angle X-Ray Scattering (SAXS), Wide Angle $X$-Ray Scattering (WAXS), and X-Ray Diffraction (XRD). Figure 8 indicates the " $\ln \left(\beta_{0} / \mathrm{T}_{\mathrm{c}}{ }^{2}\right)$ " versus " $1 / \mathrm{T}_{\mathrm{c}}$ " plot (Kissinger), the " $\log \beta_{0}$ " versus " $\log \mathrm{t}_{\mathrm{c}}$ " plot $(\mathrm{Liu})$, and the " $\beta_{0}$ " versus " $\mathrm{T}_{\mathrm{c}}$ " plot (Khanna) for PE non-isothermal crystallization in the systems investigated.

In all the cases, each plot was generated by performing DSC analysis at four different cooling rates, as explained in Section 2.6. The values of $E_{\mathcal{C}}, F(T)$, and $C R C$ are depicted in Table 4. 
Table 4. Kissinger, Liu, and Khanna crystallization parameters of PE in unfilled and filled binary systems. CRC: crystallization rate coefficient.

\begin{tabular}{cccc}
\hline & $E_{\boldsymbol{c}}(\mathrm{KJ} / \mathbf{m o l})$ & $\boldsymbol{F}(\boldsymbol{T})$ & $\boldsymbol{C R C}\left(\mathbf{m i n}^{-\mathbf{1}}\right)$ \\
\hline PE90 & $283.5( \pm 1.2)$ & $4.4( \pm 0.03)$ & $2.97( \pm 0.04)$ \\
PE90GO2 & $269.8( \pm 0.9)$ & $2.6( \pm 0.02)$ & $3.25( \pm 0.03)$ \\
PE90RGO2 & $201.7( \pm 1.1)$ & $1.3( \pm 0.02)$ & $3.74( \pm 0.04)$ \\
PE90GO4 & $276.4( \pm 1.2)$ & $3.1( \pm 0.04)$ & $3.12( \pm 0.02)$ \\
PE90RGO4 & $216.1( \pm 0.8)$ & $2.2( \pm 0.03)$ & $3.61( \pm 0.02)$ \\
\hline
\end{tabular}

(A)

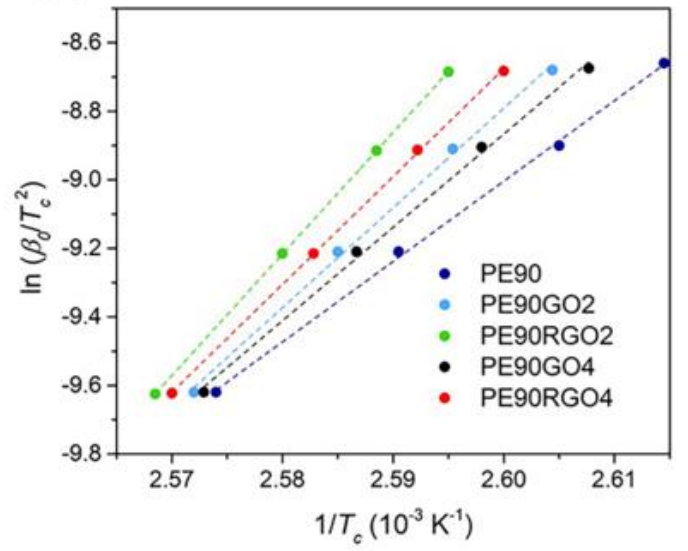

(B)

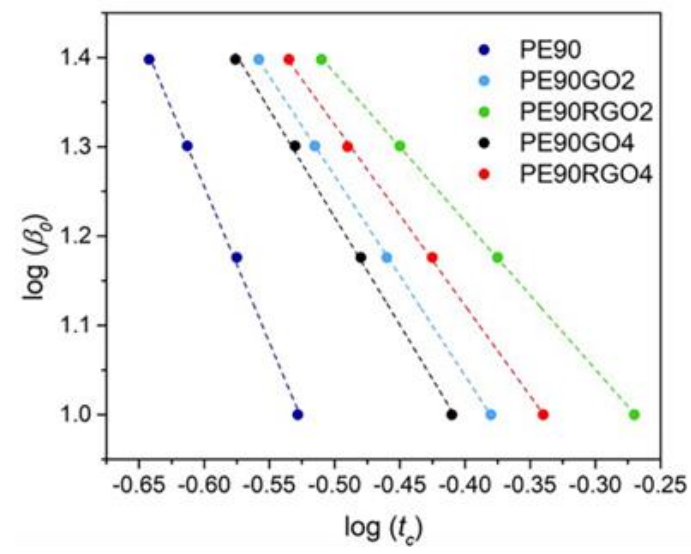

(C)

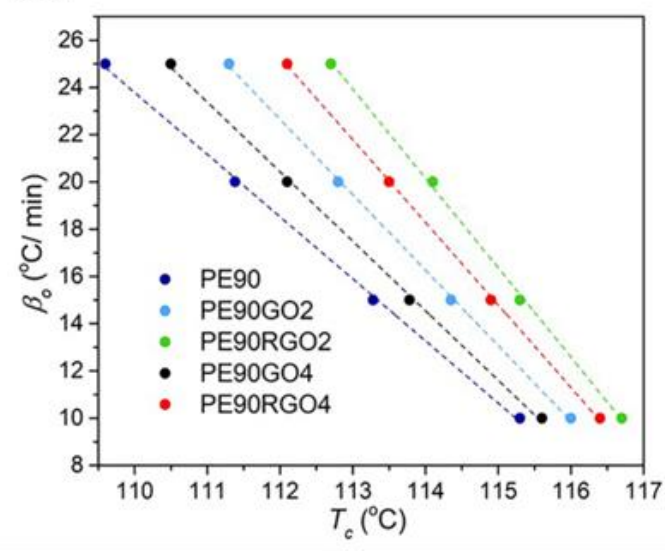

Figure 8. Kissinger (A), Liu (B), and Khanna (C) plots for PE non-isothermal crystallization in unfilled and filled binary systems.

Research studies indicate that a faster crystallization occurs at lower values of $E_{\mathcal{c}}[37,38]$ and $F(T)$ [39], as well as higher values of $C R C$ [40]. Table 4 shows that when the nucleating agent was represented by the pair PP + filler (samples PE90GO2, PE90RGO2, PE90GO4, PE90RGO4), compared to only PP (sample PE90), the $E_{c}$ and $F(T)$ of PE were always lower, while the $C R C$ of PE was always higher. This was because the employed sequential mixing induced the co-factor to be selectively localized at the biphasic system interface (Figure 2B-E), increasing its interaction with the two polymers [41] and hence improving the nucleating effect of $\mathrm{PP}$ on $\mathrm{PE}$ crystallization. Moreover, since the $E_{c}$ and $F(T)$ of $\mathrm{PE}$ were lower and $C R C$ was higher, when the filler was RGO, as opposed to GO, the PP nucleating activity on PE crystallization was more effective. This happened because the co-factor was better exfoliated and covered more interfacial area (Figure 2C); hence, it had a higher surface area of interaction with the two polymeric phases. When comparing different amounts of RGO, $E_{\mathcal{c}}$ and $F(T)$ of PE reached the 
lowest value, while $C R C$ reached the highest value when the co-factor was RGO2 instead of RGO4, demonstrating that the best nucleating effect of PP + filler on PE crystallization was reached when RGO was introduced with a $2 \%$ weight concentration, rather than $4 \%$. Consequently, in the PE90RGO2 configuration, a very uniform size distribution of PE crystals was registered, as confirmed by PLOM studies in Section 3.3. This is also validated by other works [35,36] available in the literature that study the crystallization of PE in nanocomposites, by means of SAXS, WAXS, and XRD. Overall, by pairing the outcome of studies on PE non-isothermal crystallization kinetics with those of optical microscopy, it can be claimed that in the system PE90RGO2, among all the polymeric systems investigated, PE crystallization was not only the fastest (lowest $\mathrm{E}_{\mathrm{C}}$ and $\mathrm{F}(\mathrm{T})$, as well as highest $\mathrm{CRC}$ ), but it was also characterized by the most uniform spherulite size (Figure 6C). Moreover, the experimental findings (TGA, HDT, DSC, and PLOM) agreed with the theoretical studies (crystallization kinetics), demonstrating that an improved PE non-isothermal crystallization led to a greater increase in thermal stability and heat deformation resistance for the PE-rich PE/PP/RGO ternary system.

\section{Conclusions}

GO was modified to obtain RGO, which was then thermodynamically localized at the interface of a PE-based PE/PP biphasic polyolefin system. The impact of the produced RGO on ternary system's thermal stability and heat deformation resistance was investigated. RGO-filled biphasic polyolefin systems had greater performance than those of $\mathrm{PE} / \mathrm{PP} / \mathrm{GO}$, as GO modification brought a better exfoliated co-factor, which covered the binary system interfacial area more evenly (confirmed by TEM), leading to a finer dispersion of PP into the major phase. This translated into stronger interactions between the co-factor and the two polymers, thus hindering their chains' mobility. Consequently, thermal degradation and heat deformation were delayed. In terms of different RGO loads, a stronger impact on the ternary system's performance enhancement was registered when the filler weight fraction was $2 \%$ as opposed to $4 \%$, because RGO2 had a less agglomerated configuration than RGO4. Therefore, the co-factor was more homogeneously distributed at the PE/PP interface (confirmed by TEM) and the micro phase was better dispersed into the macro phase, leading to greater synergy between the two polymers. This was also confirmed by the activation energy of thermal degradation, which was the highest for PE90RGO2. Another interesting feature of this research work was the investigation of PE non-isothermal crystallization in unfilled and filled binary systems. RGO and PP played a synergistic nucleating effect on PE crystallization, making it faster and easier, with spherulites having a more uniform size distribution (confirmed by PLOM). The most improved PE crystallization was registered when the filler was RGO2, with $E_{\mathcal{c}}, t_{c}, \Delta T$, and $F(T)$ being the lowest, and $T_{\mathcal{c}}, X_{\mathcal{c}}$, and CRC being the highest. Lastly, the TGA properties of PE90RGO2 were higher than those of neat PP, while their HDT values were found to be close to each other. This generates potential for industries, such as the energy and automotive sectors, to replace PP-rich products with those based on a more abundant, cheaper, yet performant $\mathrm{PE}$, thus satisfying the strict requirements of emerging engineering applications.

Author Contributions: Conceptualization, A.G. and M.S.; methodology, A.G.; software, A.G.; validation, S.J. and M.S.; formal analysis, A.G.; investigation, A.G.; resources, J.T., S.J., and M.S.; data curation, A.G., C.G., and O.A.T.D.; writing—original draft preparation, A.G.; writing—review and editing, A.G., O.A.T.D., S.J., J.T., and M.S.; visualization, A.G., C.G., and O.A.T.D.; supervision, S.J. and M.S.; project administration, A.G.; funding acquisition, S.J. and M.S. All authors have read and agreed to the published version of the manuscript.

Funding: This research was fund by the Ontario Research Fund-Research Excellence-07 (ORF-RE-07) program, grant number 500256.

Acknowledgments: The authors thank Christian Belachew and Mio Ren for technical assistance.

Conflicts of Interest: The authors declare no conflict of interest. 


\section{References}

1. Stuart, M.A.C.; Huck, W.T.S.; Genzer, J.; Müller, M.; Ober, C.; Stamm, M.; Sukhorukov, G.B.; Szleifer, I.; Tsukruk, V.V.; Urban, M.; et al. Emerging applications of stimuli-responsive polymer materials. Nat. Mater. 2010, 9, 101. [CrossRef] [PubMed]

2. Utracki, L.A. History of commercial polymer alloys and blends (from a perspective of the patent literature). Polym. Eng. Sci. 1995, 35, 2-17. [CrossRef]

3. Muthuraj, R.; Misra, M.; Mohanty, A.K. Biodegradable compatibilized polymer blends for packaging applications: A literature review. J. Appl. Polym. Sci. 2017, 135. [CrossRef]

4. Jordan, A.M.; Kim, K.; Soetrisno, D.; Hannah, J.; Bates, F.S.; Ja, A.; Lhost, O.; Macosko, C.W. Role of crystallization on polyolefin interfaces: An improved outlook for polyolefin blends. Macromolecules 2014. [CrossRef]

5. Kirchberger, A.; Münstedt, H. Droplet deformation under extensional flow in immiscible and partially miscible polymer blends based on poly(styrene-co-acrylonitrile). J. Rheol. 2010, 54, 687-704. [CrossRef]

6. Graziano, A.; Processing, B. Review on Modification strategies of polyethylene/polypropylene immiscible thermoplastic polymer blends for enhancing their mechanical behavior. J. Elastomers Plastics 2018, 1-36. [CrossRef]

7. Eagan, J.M.; Xu, J.; Di Girolamo, R.; Thurber, C.M.; Macosko, C.W.; LaPointe, A.M.; Bates, F.S.; Coates, G.W. Combining polyethylene and polypropylene: Enhanced performance with PE/ $i$ PP multiblock polymers. Science (80-.) 2017, 355, 814-816. [CrossRef]

8. Colbeaux, A.; Fenouillot, F.; Gerard, J.F.; Taha, M.; Wautier, H. Compatibilization of a polyolefin blend through covalent and ionic coupling of grafted polypropylene and polyethylene. II. Morphology. J. Appl. Polym. Sci. 2004, 93, 2237-2244. [CrossRef]

9. Taguet, A.; Cassagnau, P.; Lopez-Cuesta, J.M. Structuration, selective dispersion and compatibilizing effect of (nano)fillers in polymer blends. Prog. Polym. Sci. 2014, 39, 1526-1563. [CrossRef]

10. Al-Saleh, M.H. Carbon nanotube-filled polypropylene/polyethylene blends: Compatibilization and electrical properties. Polym. Bull. 2016, 73, 975-987. [CrossRef]

11. Hsieh, C.T.; Pan, Y.J.; Lin, J.H. Polypropylene/high-density polyethylene/carbon fiber composites: Manufacturing techniques, mechanical properties, and electromagnetic interference shielding effectiveness. Fibers Polym. 2017, 18, 155-161. [CrossRef]

12. Ramanathan, T.; Abdala, A.A.; Stankovich, S.; Dikin, D.A.; Herrera-Alonso, M.; Piner, R.D.; Adamson, D.H.; Schniepp, H.C.; Chen, X.; Ruoff, R.S.; et al. Functionalized graphene sheets for polymer nanocomposites. Nat. Nanotechnol. 2008, 3, 327-331. [CrossRef] [PubMed]

13. Hu, H.; Allan, C.C.K.; Li, J.; Kong, Y.; Wang, X.; Xin, J.H.; Hu, H. Multifunctional organically modified graphene with super-hydrophobicity. Nano Res. 2014, 7, 418-433. [CrossRef]

14. Zhu, S.; Tang, S.; Zhang, J.; Yang, B. Control the size and surface chemistry of graphene for the rising fluorescent materials. Chem. Commun. 2012, 48, 4527-4539. [CrossRef] [PubMed]

15. Tu, C.; Nagata, K.; Yan, S. Key factor of graphene localization on electrical conductive properties of graphene filled polyethylene/polypropylene composites during melt blending. J. Mater. Sci. Res. 2017, 6, 1-10. [CrossRef]

16. Tu, C.; Nagata, K.; Yan, S. Influence of melt-mixing processing sequence on electrical conductivity of polyethylene/polypropylene blends filled with graphene. Polym. Bull. 2017, 74, 1237-1252. [CrossRef]

17. Kissinger, H.E. Variation of peak temperature with heating rate in differential thermal analysis. J. Res. Natl. Bur. Stand. (1934) 2012, 57, 217. [CrossRef]

18. Liu, T.; Mo, Z.; Wang, S. Nonisothermal melt and cold crystallization kinetics of poly ( Ary1 Ether Ether Ketone Ketone ). Polym. Eng. Sci. 1997, 37, 568-575. [CrossRef]

19. Yao, F.; Wu, Q.; Lei, Y.; Guo, W.; Xu, Y. Thermal decomposition kinetics of natural fibers: Activation energy with dynamic thermogravimetric analysis. Polym. Degrad. Stab. 2008, 93, 90-98. [CrossRef]

20. Clemons, C.M.; Sabo, R.C.; Kaland, M.L.; Hirth, K.C. Effects of silane on the properties of wood-plastic composites with polyethylene-polypropylene blends as matrices. J. Appl. Polym. Sci. 2011, 119, 1398-1409. [CrossRef]

21. Kissinger, H.E. Reaction kinetics in differential thermal analysis. Anal. Chem. 1957, 29, 1702-1706. [CrossRef] 
22. Khanna, Y.P. A barometer of crystallization rates of polymeric materials. Polym. Eng. Sci. 1990, 30, 1615-1619. [CrossRef]

23. Ren, P.G.; Yan, D.X.; Ji, X.; Chen, T.; Li, Z.M. Temperature dependence of grapheme oxide reduced by hydrazine hydrate. Nanotechnology 2011, 22. [CrossRef]

24. Graziano, A.; Dias, O.A.T.; Garcia, C.; Jaffer, S.; Tjong, J.; Sain, M. Impact of Reduced Graphene Oxide on structure and properties of polyethylene rich binary systems for performance-based applications. Polymer (Guildf) 2020, 122622. [CrossRef]

25. Haneef, M.; Saleem, H.; Habib, A. Use of graphene nanosheets and barium titanate as fillers in PMMA for dielectric applications. Synth. Met. 2017, 223, 101-106. [CrossRef]

26. Inuwa, I.M.; Hassan, A.; Samsudin, S.A.; Mohamad Kassim, M.H.; Jawaid, M. Mechanical and thermal properties of exfoliated graphite nanoplatelets reinforced polyethylene terephthalate/polypropylene composites. Polym. Compos. 2014, 35, 2029-2035. [CrossRef]

27. Fu, C.; Zhao, G.; Zhang, H.; Li, S. Evaluation and characterization of reduced graphene oxide nanosheets as anode materials for lithium-ion batteries. Int. J. Electrochem. Sci. 2013, 8, 6269-6280.

28. Song, P.; Cao, Z.; Cai, Y.; Zhao, L.; Fang, Z.; Fu, S. Fabrication of exfoliated graphene-based polypropylene nanocomposites with enhanced mechanical and thermal properties. Polymer (Guildf) 2011, 52, 4001-4010. [CrossRef]

29. Kim, H.S.; Lee, B.H.; Lee, S.; Kim, H.J.; Dorgan, J.R. Enhanced interfacial adhesion, mechanical, and thermal properties of natural flour-filled biodegradable polymer bio-composites. J. Therm. Anal. Calorim. 2011, 104, 331-338. [CrossRef]

30. Li, M.; Jeong, Y.G. Poly(ethylene terephthalate)/exfoliated graphite nanocomposites with improved thermal stability, mechanical and electrical properties. Compos. Part A Appl. Sci. Manuf. 2011, 42, 560-566. [CrossRef]

31. Laoutid, F.; Estrada, E.; Michell, R.M.; Bonnaud, L.; Müller, A.J.; Dubois, P. The influence of nanosilica on the nucleation, crystallization and tensile properties of PP-PC and PP-PA blends. Polymer (Guildf) 2013, 54, 3982-3993. [CrossRef]

32. Chen, H.L. Miscibility and crystallization behavior of poly(ethylene terephthalate)/poly(ether imide) blends. Macromolecules 1995, 28, 2845-2851. [CrossRef]

33. Gopakumar, T.G.; Lee, J.A.; Kontopoulou, M.; Parent, J.S. Influence of clay exfoliation on the physical properties of montmorillonite/polyethylene composites. Polymer (Guildf) 2002, 43, 5483-5491. [CrossRef]

34. Kim, S.H.; Ahn, S.H.; Hirai, T. Crystallization kinetics and nucleation activity of silica nanoparticle-filled poly(ethylene 2,6-naphthalate). Polymer (Guildf) 2003, 44, 5625-5634. [CrossRef]

35. Heeley, E.L.; Hughes, D.J.; El, Y.; Taylor, P.G.; Bassindale, A.R. Morphology and crystallization kinetics of polyethylene/long alkyl-chain substituted Polyhedral Oligomeric Silsesquioxanes ( POSS ) nanocomposite blends: A SAXS/WAXS study. Eur. Polym. J. 2014, 51, 45-56. [CrossRef]

36. Amoroso, L.; Heeley, E.L.; Nishal, S.; Mcnally, T. Crystallisation behaviour of composites of HDPE and MWCNTs: The effect of nanotube dispersion, orientation and polymer deformation. Polymer (Guildf) 2020, 201, 122587. [CrossRef]

37. Abareshi, M.; Zebarjad, S.M.; Goharshadi, E.K. Non-isothermal crystallization kinetics of polyethylene-clay nanocomposites prepared by high-energy ball milling. Bull. Mater. Sci. 2014, 37, 1113-1121. [CrossRef]

38. Li, X.; Guo, W.; Zhou, Q.; Xu, S.; Wu, C. Non-isothermal crystallization kinetics of poly (ethylene terephthalate)/grafted carbon black composite. Polym. Bull. 2007, 59, 685-697. [CrossRef]

39. Fan, Q.; Duan, F.; Guo, H.; Wu, T. Non-isothermal crystallization kinetics of polypropylene and hyperbranched polyester blends. Chin. J. Chem. Eng. 2015, 23, 441-445. [CrossRef]

40. Chen, Y.; Zou, H.; Liang, M.; Cao, Y. Melting and crystallization behavior of partially miscible high density polyethylene/ethylene vinyl acetate copolymer (HDPE/EVA) blends. Thermochim. Acta 2014, 586, 1-8. [CrossRef]

41. Lan, Y.; Liu, H.; Cao, X.; Zhao, S.; Dai, K.; Yan, X.; Zheng, G.; Liu, C.; Shen, C.; Guo, Z. Electrically conductive thermoplastic polyurethane/polypropylene nanocomposites with selectively distributed graphene. Polymer (United Kingdom) 2016, 97, 11-19. [CrossRef]

(C) 2020 by the authors. Licensee MDPI, Basel, Switzerland. This article is an open access article distributed under the terms and conditions of the Creative Commons Attribution (CC BY) license (http://creativecommons.org/licenses/by/4.0/). 